\title{
The role of tumor necrosis factor-like weak inducer of apoptosis in atherosclerosis via its two different receptors (Review)
}

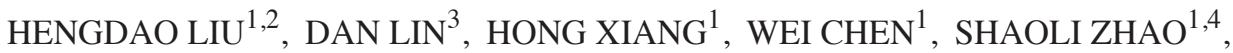 \\ HUI PENG ${ }^{1}$, JIE YANG ${ }^{1}$, PAN CHEN ${ }^{1}$, SHUHUA CHEN ${ }^{1}$ and HONGWEI LU ${ }^{1,2}$ \\ ${ }^{1}$ Center for Experimental Medical Research; ${ }^{2}$ Department of Cardiology, The Third Xiangya Hospital of Central South \\ University, Changsha, Hunan 410013; ${ }^{3}$ Qingdao Center for Disease Control and Prevention, Qingdao, Shandong 266033; \\ ${ }^{4}$ Department of Endocrinology, The Third Xiangya Hospital of Central South University, Changsha, Hunan 410013, P.R. China
}

Received May 3, 2016; Accepted March 31, 2017

DOI: $10.3892 /$ etm.2017.4600

\begin{abstract}
At present, it is commonly accepted that atherosclerosis is a chronic inflammatory disease characterized by disorder of the arterial wall. As one of the inflammatory cytokines of the tumor necrosis factor superfamily, tumor necrosis factor-like weak inducer of apoptosis (TWEAK) participates in the formation and progression of atherosclerosis. TWEAK, when binding to its initial receptor, fibroblast growth factor inducible molecule 14 (Fn14), exerts adverse biological functions in atherosclerosis, including dysfunction of endothelial cells, phenotypic change of smooth muscle cells and inflammatory responses of monocytes/macrophages. However, accumulating data supports that, besides Fn14, TWEAK also binds to cluster of differentiation (CD)163, an anti-inflammatory cytokine and a scavenger receptor exclusively expressed by monocytes and macrophages. Furthermore, it has been demonstrated that CD163 is able to internalize TWEAK and likely elicits protective effects in atherosclerosis by terminating inflammation induced by TWEAK. In the present study, the role of TWEAK in atherosclerosis was reviewed, with a predominant focus on CD163 and Fn14 receptors.
\end{abstract}

\section{Contents}

1. Introduction

2. Fn14: The first definite receptor

3. CD163: The second definite receptor

4. Therapeutic considerations

5. Conclusions

Correspondence to: Professor Hongwei $\mathrm{Lu}$, Center for Experimental Medical Research, The Third Xiangya Hospital of Central South University, 138 Tong-Zi-Po Road, Changsha, Hunan 410013, P.R. China

E-mail: hwlv2226@163.com

Key words: tumor necrosis factor-like weak inducer of apoptosis, fibroblast growth factor inducible molecule 14, cluster of differentiation 163 , receptor, atherosclerosis

\section{Introduction}

Atherosclerosis remains a major global challenge (1). The World Health Organization statistics data suggest that, by 2020, atherosclerosis will be the most common cause of death and morbidity in both developed and developing countries (2). Atherosclerosis has long been studied as a chronic inflammatory disorder of the arterial wall, which involves numerous cytokines. Accumulating data suggests that one of the cytokines, tumor necrosis factor-like weak inducer of apoptosis (TWEAK), is heavily involved in the formation and progression of atherosclerosis (3-8). TWEAK is encoded by the tumor necrosis factor ligand superfamily (TNFSF) member 12 gene in the tumor TNFSF and its role as a multifunctional cytokine was recognized in a previous study (9). Similar to other ligands of TNFSF, TWEAK is initially synthesized as a type II transmembrane protein with 249 amino acids and is subsequently cut by furin to release smaller and soluble fragments known as STWEAK, which mediate different biological effects (9-11). The role of TWEAK interactions with related receptors in atherosclerosis development have been elaborated by experiments in vitro and in vivo, and fibroblast growth factor inducible molecule 14 (Fn14), the first reported receptor of TWEAK, is a related receptor (12-17). Another receptor, cluster of differentiation (CD)163, has also been identified as a receptor of TWEAK (18). CD163 is widely acknowledged as a scavenger receptor and an anti-inflammatory molecule (18). Therefore, it is not surprising that there is now an increased interest in the interaction of TWEAK and CD163 in atherosclerosis (19-21). In the present article, the function of Fn14 and CD163 receptors and TWEAK in atherosclerosis was investigated.

\section{Fn14: The first definite receptor}

Fn14 expression and signaling. Fn14 was the first widely recognized TWEAK receptor. Given its one single cysteine-rich domain (CRD), it is generally considered as the smallest member of the tumor necrosis factor receptor (TNFR) superfamily (11). Originally, Fn14 was identified to be induced by fibroblast growth factor (FGF)1 (22) and subsequent studies discovered that various other growth factors, including FGF2, 
platelet-derived growth factor and epidermal growth factor, and cytokines such as tumor necrosis factor (TNF)- $\alpha$, interleukin (IL)- $1 \beta$, transforming growth factor- $\beta$ and interferon- $\gamma$, are able to induce Fn14 expression (22-25).

The chromosomal position of the human Fn14 gene is at 16 p13.3 (23). The Fn14 gene initially encodes a Fn14 type I transmembrane 129-amino acid protein that transforms to a mature form (23). In the TNFR superfamily, the cytoplasmic domain of Fn14 is the shortest, with only 28 amino acids (11). Similar to TNF- $\alpha$ and other members in the family, Fn14 contains a TNF receptor-associated factor (TRAF) binding site that recruits and binds to TRAF adapter proteins (24). The association may provoke the activation of nuclear factor $(\mathrm{NF})-\kappa \mathrm{B}$. Notably, TWEAK, is able to induce prolonged NF- $\kappa B$ activation compared with TNF (26).

In contrast to its substantial expression in injured and morbid tissues, Fn14 is rarely expressed in healthy tissues, which distinguishes it from TWEAK (26). Studies have indicated that Fn14 is expressed in the liver following partial hepatectomy and chemical injury $(27,28)$, in the vasculature following balloon catheter injury (22), in the kidney after acute kidney injury and in the heart after myocardial infarction (29). Regarding the vascular wall, Fn14 expression is scarce in non-atherosclerotic arteries whereas TWEAK is typically expressed (15). However, in human atherosclerotic plaques, both TWEAK and Fn14 are expressed in vascular smooth muscle cells (VSMCs) and macrophages, suggesting that Fn14 may interact with TWEAK on damaged vessel walls, which may lead to adverse outcomes in atherosclerotic lesions (30).

Fn14 in atherosclerosis. Atherosclerosis is generally considered as a chronic inflammatory disease with dysfunction of various cells, including macrophages, smooth muscle cells and endothelial cells $(15,31,32)$. The interaction between TWEAK and Fn14 may potentially stimulate the proliferation and migration of cells and induce cell inflammatory responses, which are critical steps in developing atherosclerotic plaques (32). The joint function of TWEAK and Fn14 in disturbing endothelial cells, altering the phenotypes of smooth muscle cells and triggering the inflammatory response of monocytes/macrophages, respectively, will be discussed in subsequent sections.

Dysfunction of endothelial cells. Normal, healthy endothelium is characterized by its anticoagulant, antiplatelet and fibrinolytic properties, which are essential in cardiovascular control (33). However, these functional properties are easily responsive to stimuli due to the mutable nature of vascular endothelium. One type of mutation, phenotypic modulation, may result in dysfunctional state of vascular endothelium, which is now recognized as the possible initial step in developing atherosclerosis (33). One important phenotypic activation biomarker is the expression of adhesion molecules $(15,33)$. These molecules include selectins, intercellular adhesion molecules (ICAMs) and vascular adhesion molecules (VCAMs), which activate and accumulate local monocytes $(15,33)$. As a result, monocytes are able to migrate into subendothelial areas and differentiate into macrophages. These differentiated macrophages are able to uptake oxidized low density lipoproteins (ox-LDLs).

TWEAK induces the expression of adhesion molecules, such as E-selectin and ICAM-1, on the cell surface of human umbilical vein endothelial cells (HUVECs), which have been investigated in vitro (34). Furthermore, researchers have demonstrated that Fn14 mediates these processes by blocking monoclonal antibody against human Fn14 (34). TWEAK and Fn14 have been indicated in HUVECs to jointly induce monocyte chemoattractant protein-1 (MCP-1) and IL-8 secretion, which predominantly recruits monocytes and neutrophils (15) (Fig. 1A).

Phenotypic change of smooth muscle cells. Through contraction, VSMCs partially maintain vascular tone and diameter (35). Contrary to skeletal and cardiac myocytes, VSMCs are not terminally differentiated and preserve remarkable phenotypic and functional plasticity in order to respond to various stimuli (36). In developing atherosclerosis, VSMCs in the quiescent 'contractile' phenotype are prone to transform into the 'proinflammatory' phenotype; a phenotype with a superior ability to proliferate and migrate (36). Previous studies have indicated that transformation to this 'novel' VSMC phenotype may be elicited by TWEAK/Fn14 interaction $(34,37,38)$. Therefore, we have reason to believe that TWEAK/Fn14 interaction is involved in the formation of atherosclerotic plaques by thickening neointimal.

Plaque rupture or erosion, secondary to complete or incomplete occlusive thrombosis, reflects the pathophysiological process of an acute cardiovascular and cerebrovascular event related to atherosclerosis (14). Tissue factor (TF), plasminogen activator inhibitor 1 (PAI-1) and various alternative molecules are responsible for thrombosis, of which TF is the primary molecule involved in initiating a clotting cascade $(39,40)$. TFs are identified in cellular pools in smooth muscle cells (SMCs) and released in microparticles from SMCs (41). Compared to SMCs in normal arterial tissue and adjacent media, PAI-1 is increasingly expressed in SMCs within the fibrous cap (42). This increase in expression is critical for inhibiting fibrinolysis $(43,44)$. In human carotid atherosclerotic plaques, Fn14 has been revealed to be colocalized with both PAI-1 and TF (14). Similarly, in cultured human aortic SMCs, TWEAK has been observed to induce both TF and PAI-1 expression and activation (14). Furthermore, with Fn14 small interfering (si)RNA or an anti-Fn14 blocking antibody, the increase in expression and activity of PAI-1 and TF is curbed (Fig. 1B).

Inflammatory response of monocytes/macrophages. Monocytes/macrophages are involved in atherosclerosis by generating numerous proinflammatory cytokines (45) and participate in all stages of lesion development. Assisted by MCP-1 and other chemokines, monocytes are recruited to endothelium and subsequently, due to high expression level of endothelial adhesion molecules (such as ICAM-1 and VCAM), monocytes continue to move into the subendothelial space to differentiate into macrophages $(15,26)$. Following this, monocyte-derived macrophages, induced by ox-LDL, begin to proliferate and extend inflammatory responses (46), thereby increasing the secretion of proinflammatory cytokines, such as IL-6 and -8, and matrix metalloproteinases (MMPs), including MMP-9 (31). Production of proinflammatory cytokines exacerbates the progression of atherosclerosis. Furthermore, MMPs degrade collagen in the fibrotic cap, resulting in more-prone-to rupture atherosclerotic plaques (15). 


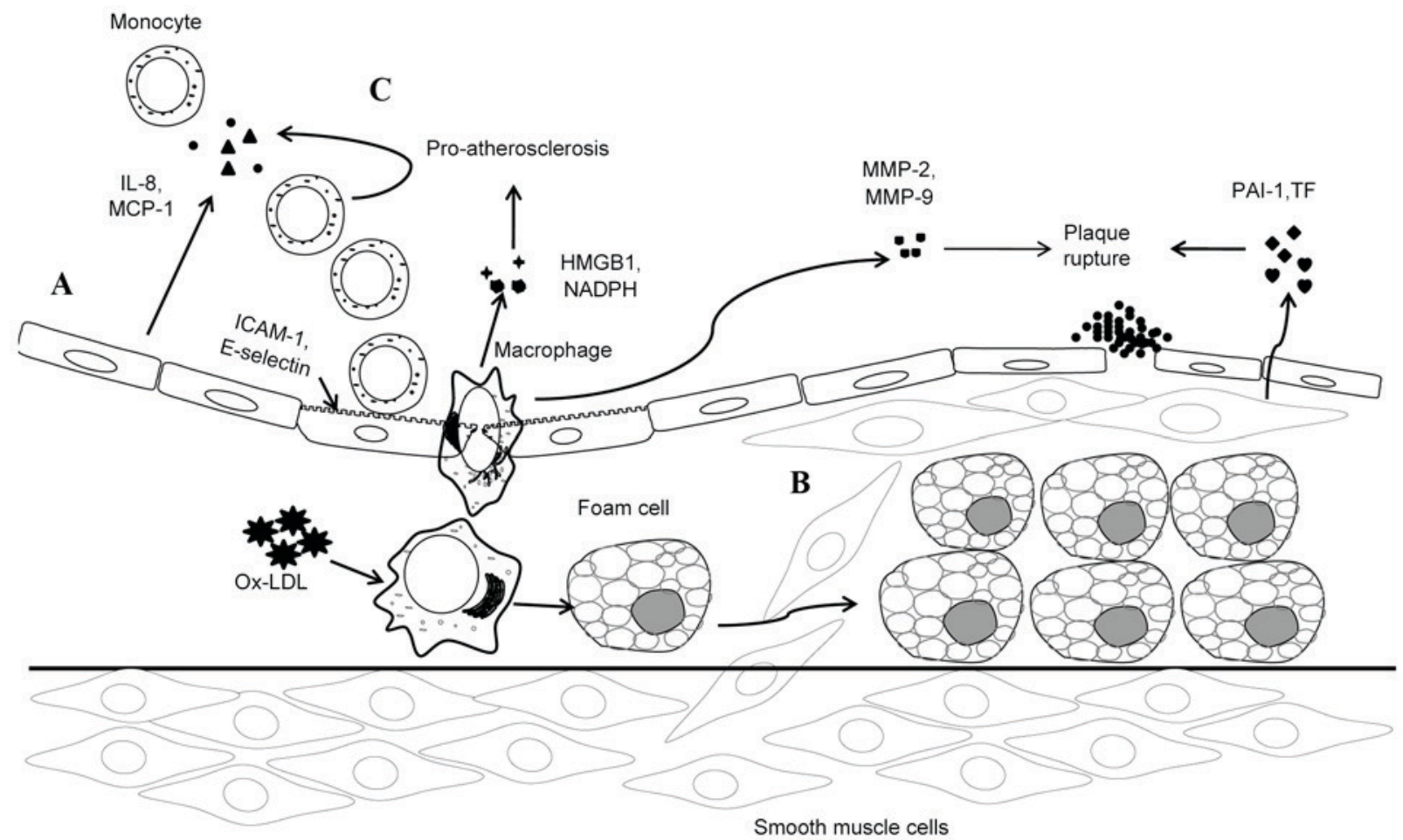

Figure 1. Fn14 in atherosclerosis. (A) TWEAK/Fn14 axis induces the expression of adhesion molecules, such as E-selectin and ICAM-1, in endothelial cells, which results in the activation and accumulation of local monocytes. TWEAK/Fn14 axis also induces the secretion of MCP-1 and IL-8 in endothelial cells, which may recruit monocytes. (B) TWEAK/Fn14 axis elicits the function of promoting proliferation and migration of VSMCs. Expression of the thrombosis mediators, TF and PAI-1, may be induced by this axis. (C) TWEAK/Fn14 axis may induce the expression of MCP-1 and IL-8 in activated monocytes and MMP-9 and HMGB1 in macrophages. The TWEAK/Fn14 axis also assists NADPH oxidase activation, thereby generating oxygen species in macrophages. In addition, the axis alters macrophage trafficking and increases lipid uptake of macrophages. TWEAK, tumor necrosis factor-like weak inducer of apoptosis; Fn14, fibroblast growth factor inducible molecule 14; ICAM, intercellular adhesion molecule; MCP-1, monocyte chemoattractant protein-1; IL, interleukin; VSMCs, vascular smooth muscle cells; MMP, matrix metalloproteinases; HMGB1, high mobility group box 1; Ox-LDL, oxidized low density lipoprotein; PAI-1, plasminogen activator inhibitor 1; TF, tissue factor.

The effects of the TWEAK/Fn14 axis on monocytes/macrophages have been supported by several studies (47-49). By inhibiting the biological function of TWEAK at Fn14 with Fn14-Fc, a study by Schapira et al (47) demonstrated that TWEAK and Fn14 interactions may alter macrophage trafficking and increase lipid uptake of macrophages. Additionally, TWEAK was revealed to induce various proinflammatory mediators of atherogenesis, such as IL-6, MCP-1 and IL-8 in activated monocytes (48). There is also evidence that TWEAK is able to enhance MMP-9 and -2 protease activity in apolipoprotein E knockout mice (49).

It is well-acknowledged that oxidative stress is associated with inflammation and the development of atherosclerosis $(50,51)$. In this scenario, TWEAK assists NADPH oxidase activation, thereby generating reactive oxygen species (ROS) in macrophages (12). Furthermore, NADPH oxidase activity and ROS production are unsurprisingly compromised by siRNA against Fn14. Therefore, binding to Fn14 may mediate the role of TWEAK in the context of oxidative stress (12).

High mobility group box 1 (HMGB1) is a DNA-binding cytokine released from necrotic cells (52) and activated macrophages (53). HMGB1 stimulates monocytes/macrophages to express proinflammatory cytokines that mediate the inflammatory response in atherosclerotic plaque development (54). The TWEAK/Fn14 axis has been demonstrated to induce monocytes/macrophages to express and secrete HMGB1 (13). Furthermore, it has been indicated that both HMGB1 and
TWEAK/Fn14 were expressed by macrophages (55) in human atherosclerotic plaques (30). Additionally, a previous study supported this observation in the shoulder region of human atherosclerotic plaques, where HMGB1 was colocalized with TWEAK/Fn14 (13). Therefore, the fact that anti-Fn14 blocking antibody is able to block the upregulation of HMGB1 by TWEAK in cultured monocytes supports the notion that Fn14 mediates the functions of TWEAK. In addition, the same conclusion of HMGB1 expression induced by TWEAK may be drawn in atherosclerotic plaques of hyperlipidemic apolipoprotein E-null mice (13) (Fig. 1C).

\section{CD163: The second definite receptor}

Introduction. CD163 is a $130-\mathrm{kDa}$ member of the scavenger receptors and is exclusively expressed by monocytes and macrophages (56). CD163 is a marker for anti-inflammatory activity in macrophages (57) and is potentially a newly identified receptor for TWEAK, as reported previously $(18,21)$. Increasing in vivo and in vitro evidence suggests that the interaction between TWEAK and CD163 may affect the development of atherosclerosis and related diseases $(19,20,57-60)$.

CD163 expression and structure. CD163 is a type I transmembrane protein that belongs to group $\mathrm{B}$ of the scavenger receptor cysteine-rich (SRCR) superfamily (61). According to the number of cysteine residues in each SRCR domain, 
receptors in the SRCR superfamily are divided into groups A and B (62). CD163 consists of nine consecutive SRCR class B domains in the extracellular domain and its transmembrane moiety spans the plasma membrane once (61). In addition, CD163 has a short intracellular tail that shares consensus sequences for phosphorylation with protein kinase $\mathrm{C}$ and creatine kinase (61). Furthermore, in plasma and body fluids, such as synovial fluids, CD163 is present in another form, sCD163, which is a soluble protein (61). Interestingly, sCD163 spans $>94 \%$ of the extracellular domain, including all SRCR domains (63).

Cellular expression of CD163 is limited to monocyte/macrophage lineage (56), of which, tissue macrophages (such as macrophages in atherosclerotic plaques, Kupffer cells in the liver and red pulp macrophages in the spleen) are principal sites $(21,64)$. CD163 is highly expressed in these mature tissue macrophages, whereas its expression level is modest in monocytes (65). This is important because it distinguishes CD163 as a differentiation marker of the macrophage lineage with increased expression along the macrophage differentiation pathway $(65,66)$. Studies have demonstrated CD163-expressing macrophages in a number of diseases associated with inflammation, including arthritic joints (67), tumors (68) and atherosclerosis (69). However, CD163 expression is strongly regulated by multiple pro- and anti-inflammatory mediators, as in vitro studies have indicated $(65,70-75)$. Of all mediators, those with anti-inflammatory effects, such as IL-10 and glucocorticoids, are considered the most potent stimulators of CD163 expression (71,74,76-79). In contrast, pro-inflammatory cytokines, both endogenous (such as IL- 8 and TNF- $\alpha$ ) and exogenous (such as lipopolysaccharides), suppress CD163 expression $(71,79,80)$. Notably, several anti-inflammatory mediators, including IL-4 and -1, inhibit CD163 expression $(71,81)$. It should be noted that IL- 6 exerts both pro- and anti-inflammatory effects on mononuclear phagocytes and increases CD163 expression (74).

CD163-a receptor for hemoglobin-haptoglobin ( $\mathrm{Hp}-\mathrm{Hb}$ ) clearance. At present, CD163 is generally considered to be a scavenger receptor of $\mathrm{Hb}-\mathrm{Hp}$ complexes (56), which has been extensively studied. Intraplaque hemorrhage and subsequent rupture of immature neointimal vasa vasorum releases cell-free $\mathrm{Hb}(82,83)$. $\mathrm{Hb}$ and $\mathrm{Hb}$-derived products are able to enhance oxidative stress and inflammation, thereby imposing an adverse impact on atherosclerotic plaque progression (84). However, $\mathrm{Hb}$ may be cleared by CD163. Once released from erythrocytes, during the process of binding to Hp to form $\mathrm{Hb}-\mathrm{Hp}$ complexes, $\mathrm{Hb}$ exposes a neo-epitope that is able to combine with CD163 $(56,85)$. Hb-Hp-CD163 binding accelerates the degradation of the complex (64). Once the receptor-ligand complex is delivered to early endosomes through endocytosis, CD163 is dissociated and recycled to cell membrane, whereas Hb-Hp continues its metabolism within lysosomes (86). Regulated by the rate-limiting enzyme, heme oxygenase-1 (HO-1), $\mathrm{Hb}-\mathrm{Hp}$ metabolism produces anti-inflammatory molecules, including biliverdin, free iron and carbon monoxide $(87,88)$. Conversely, HO-1 and CD163 production may be upregulated by IL-10, and production of IL-10 is triggered by Hb-Hp-CD163 binding (87) (Fig. 2A).

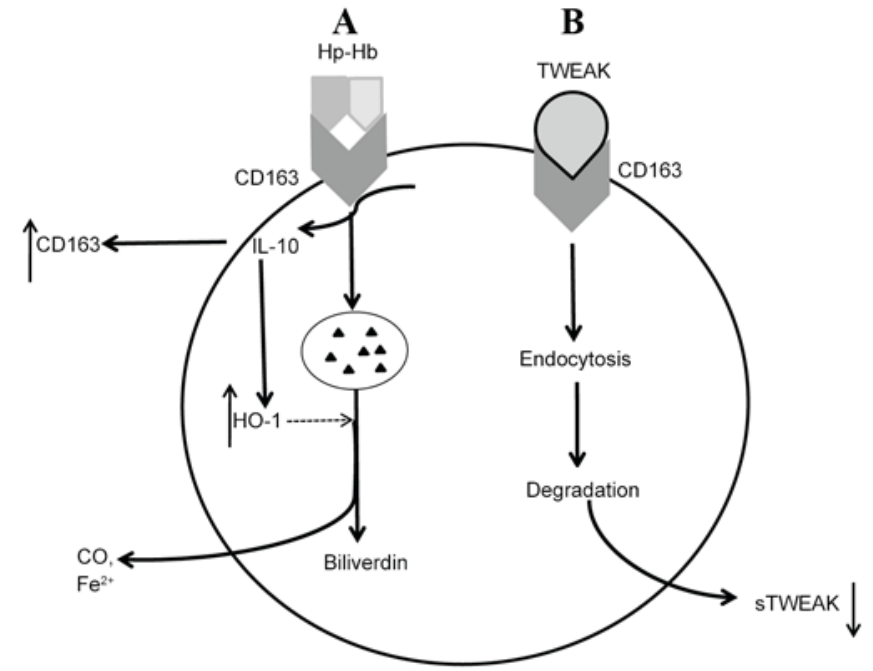

Figure 2. CD163 in atherosclerosis. (A) Hb may be scavenged by CD163. Once released from erythrocytes, $\mathrm{Hb}$ binds to $\mathrm{Hp}$ to form complexes, resulting in exposure of a neo-epitope that is able to combine with CD163. Once this receptor-ligand complex is delivered to early endosomes through endocytosis, CD163 enters an alternative pathway by dissociating and is recycled to cell membrane, whereas $\mathrm{Hb}-\mathrm{Hp}$ continues its metabolism within the lysosomes. Regulated by the rate-limiting enzyme, $\mathrm{HO}-1, \mathrm{Hb}-\mathrm{Hp}$ metabolism produces anti-inflammatory molecules, including biliverdin, $\mathrm{Fe}^{2+}$ and $\mathrm{CO}$. Conversely, HO-1 and CD163 production may be upregulated by IL-10, whose production is triggered by $\mathrm{Hb}-\mathrm{Hp}-\mathrm{CD} 163$ binding through activating the intracellular signaling pathway. (B) CD163-expressing macrophages recognize and internalize TWEAK, resulting in a decrease of sTWEAK. TWEAK, tumor necrosis factor-like weak inducer of apoptosis; sTWEAK, soluble TWEAK; HO-1, heme oxygenase-1; CD163, cluster of differentiation 163; Hb, hemoglobin; Hp, haptoglobin; IL, interleukin; $\mathrm{CO}$, carbon monoxide; $\mathrm{Fe}^{2+}, \mathrm{Iron}^{2+}$.

CD163 and TWEAK. Besides Hb-Hp complexes, CD163 is also a scavenger receptor for TWEAK. In 2003, when Fn14 was considered as the exclusive receptor of TWEAK, a study by Polek et al (89) indicated that cells lacking Fn14 were still sensitive to TWEAK, indicating the existence of another TWEAK receptor. This alternative TWEAK-binding protein was identified as CD163, via a random combinatorial peptide library (18). Then, Moreno et al (21) first reported first reported the potential role of TWEAK-CD163 binding in atherosclerosis development. Subsequent research suggested that CD163-expressing macrophages reduced endogenous TWEAK expression and were able to bind and degrade TWEAK that was added exogenously from supernatants in vitro (21). Therefore, CD163 may inhibit TWEAK, which may further relieve inflammation in atherosclerosis (90).

Moreno et al (91) observed that SCD163 and sTWEAK levels were negatively correlated in cultured human atherothrombotic femoral plaque samples and patients with atherothrombosis-derived peripheral artery diseases. Additionally, these patients exhibited a significantly increased SCD163/sTWEAK ratio that was positively correlated with the severity of their diseases (91). Accordingly, the sCD163/sTWEAK ratio may act as an indicator of atherothrombosis progression (91). Similar results were revealed in other atherosclerotic related diseases such as coronary artery disease with or without chronic kidney disease $(19,20,58)$. It seems counterfactual that, as an inflammatory factor, sTWEAK concentration decreased in these atherosclerotic related diseases $(19,20,58)$. Unfortunately, the mechanism by which this occurs is not fully understood. 
One possible and mostly accepted explanation is that binding of circulating TWEAK molecules to its receptors creates a decrease in STWEAK. One of these receptors is CD163 and is typically upregulated in chronic inflammatory activation $(92,93)$. In addition, the biological activity of sTWEAK is largely mediated by Fn14 (90), which may be scavenged, by CD163 binding to TWEAK, and deactivated. In this case, decreased concentrations of STWEAK may be attributed to the increase of soluble CD163 (20) (Fig. 2B).

\section{Therapeutic considerations}

The possible contradictory outcomes that TWEAK exerts when binding to the two different receptors, Fn14 and CD163, offers a novel therapeutic view in treating atherosclerosis. It is well-acknowledged that statins are an anti-atherosclerosis medication that regulate blood lipid metabolism and reduce the levels of circulating LDL by inhibiting the activity of hydroxy-methyl-glutaryl Coenzyme A reductase (HMG-CoA reductase), a key enzyme in the cholesterol biosynthesis pathway (94). Statins, or HMG-CoA reductase inhibitors, are able to decrease Fn14 expression in human SMCs and carotid atherosclerotic plaques (30). Furthermore, atorvastatin also reduces the proinflammatory response induced by TWEAK in human SMCs (30). Therefore, these findings indicate that statins may potentially have a novel effect in atherosclerosis treatment. Additionally, the TWEAK/Fn14 combination may become a novel target of interference in atherosclerosis development. As for CD163, in addition to its potential diagnostic uses in atherosclerosis-related diseases, it is also an interesting candidate for medical therapy $(19,57,58,60)$. This is because CD163, as an example of the atheroprotective intraplaque population, eliminates free-Hb and releases a large quantity of anti-inflammatory mediators via activating downstream pathways $(62,64)$. Additionally, CD163 has the potential to diminish inflammation in atherosclerosis by recognizing and internalizing TWEAK.

\section{Conclusions}

In conclusion, TWEAK functions divergently when binding to the two receptors, Fn14 and CD163. Regarding Fn14, TWEAK imposes adverse effects by encouraging atherosclerosis development, including disturbing endothelial cells, changing phenotypes of smooth muscle cells and triggering inflammatory response of monocytes/macrophages. However, when interacting with CD163, TWEAK may elicit potential protective effects. Currently, the mechanism by which the downstream pathway is activated following the recognition and internalization of TWEAK by CD163 and whether this activated pathway is similar to the result of CD163 binding to the $\mathrm{Hp}-\mathrm{Hb}$ complex is unclear. Further study in vivo is required to elucidate the effect of the TWEAK/CD163 axis.

\section{Acknowledgements}

The present study was supported by funding from the National Basic Research Program of China (grant no. 2014CB542400), the National Natural Science Foundation of China (grant nos. 81470593 and 81300053) and the Research Innovation
Program for Graduate Students of Central South University (grant no. 2016zzts152).

\section{References}

1. Linden F, Domschke G, Erbel C, Akhavanpoor M, Katus HA and Gleissner CA: Inflammatory therapeutic targets in coronary atherosclerosis-from molecular biology to clinical application. Front Physiol 5: 455, 2014.

2. Scott J: The pathogenesis of atherosclerosis and new opportunities for treatment and prevention. J Neural Transm Suppl: 1-17, 2002.

3. Tedgui A and Mallat Z: Cytokines in atherosclerosis: Pathogenic and regulatory pathways. Physiol Rev 86: 515-581, 2006.

4. Blanco-Colio LM, Martin-Ventura JL, Carrero JJ, Yilmaz MI, Moreno JA, Gómez-Guerrero C, Ortiz A and Egido J: Vascular proteomics and the discovery process of clinical biomarkers: The case of TWEAK. Proteomics Clin Appl 5: 281-288, 2011.

5. Jelic-Ivanović Z, Bujisić N, Spasić S, Bogavac-Stanojević N, Spasojević-Kalimanovska V and Kotur-Stevuljević J: Circulating sTWEAK improves the prediction of coronary artery disease. Clin Biochem 42: 1381-1386, 2009.

6. Kralisch S, Ziegelmeier M, Bachmann A, Seeger J, Lössner U, Blüher M, Stumvoll M and Fasshauer M: Serum levels of the atherosclerosis biomarker sTWEAK are decreased in type 2 diabetes and end-stage renal disease. Atherosclerosis 199: 440-444, 2008.

7. Blanco-Colio LM, Martín-Ventura JL, Muñóz-García B, Orbe J, Páramo JA, Michel JB, Ortiz A, Meilhac O and Egido J: Identification of soluble tumor necrosis factor-like weak inducer of apoptosis (sTWEAK) as a possible biomarker of subclinical atherosclerosis. Arterioscler Thromb Vasc Biol 27: 916-922, 2007.

8. Munoz-García B, Moreno JA, López-Franco O, Sanz AB, Martín-Ventura JL, Blanco J, Jakubowski A, Burkly LC, Ortiz A, Egido J and Blanco-Colio LM: Tumor necrosis factor-like weak inducer of apoptosis (TWEAK) enhances vascular and renal damage induced by hyperlipidemic diet in ApoE-knockout mice. Arterioscler Thromb Vasc Biol 29: 2061-2068, 2009.

9. Chicheportiche Y, Bourdon PR, Xu H, Hsu YM, Scott H, Hession C, Garcia I and Browning JL: TWEAK, a new secreted ligand in the tumor necrosis factor family that weakly induces apoptosis. J Biol Chem 272: 32401-32410, 1997.

10. Bodmer JL, Schneider P and Tschopp J: The molecular architecture of the TNF superfamily. Trends Biochem Sci 27: 19-26, 2002.

11. Wiley SR, Cassiano L, Lofton T, Davis-Smith T, Winkles JA, Lindner V, Liu H, Daniel TO, Smith CA and Fanslow WC: A novel TNF receptor family member binds TWEAK and is implicated in angiogenesis. Immunity 15: 837-846, 2001.

12. Madrigal-Matute J, Fernandez-Laso V, Sastre C, Llamas-Granda P, Egido J, Martin-Ventura JL, Zalba G and Blanco-Colio LM: TWEAK/Fn14 interaction promotes oxidative stress through NADPH oxidase activation in macrophages. Cardiovasc Res 108: 139-147, 2015.

13. Moreno JA, Sastre C, Madrigal-Matute J, Muñoz-García B, Ortega L, Burkly LC, Egido J, Martín-Ventura JL and Blanco-Colio LM: HMGB1 expression and secretion are increased via TWEAK-Fn14 interaction in atherosclerotic plaques and cultured monocytes. Arterioscler Thromb Vasc Biol 33: 612-620, 2013.

14. Muñoz-Garcia B, Madrigal-Matute J, Moreno JA, Martin-Ventura JL, López-Franco O, Sastre C, Ortega L, Burkly LC, Egido J and Blanco-Colio LM: TWEAK-Fn14 interaction enhances plasminogen activator inhibitor 1 and tissue factor expression in atherosclerotic plaques and in cultured vascular smooth muscle cells. Cardiovasc Res 89: 225-233, 2011.

15. Blanco-Colio LM, Martín-Ventura JL, Munoz-Garcia B, Moreno JA, Meilhac O, Ortiz A and Egido J: TWEAK and Fn14. New players in the pathogenesis of atherosclerosis. Front Biosci 12: 3648-3655, 2007.

16. Nakayama M, Harada $N$, Okumura $K$ and Yagita $H$ : Characterization of murine TWEAK and its receptor (Fn14) by monoclonal antibodies. Biochem Biophys Res Commun 306: 819-825, 2003.

17. Wiley SR and Winkles JA: TWEAK, a member of the TNF superfamily, is a multifunctional cytokine that binds the TweakR/Fn14 receptor. Cytokine Growth Factor Rev 14: 241-249, 2003. 
18. Bover LC, Cardó-Vila M, Kuniyasu A, Sun J, Rangel R, Takeya M, Aggarwal BB, Arap W and Pasqualini R: A previously unrecognized protein-protein interaction between TWEAK and CD163: Potential biological implications. J Immunol 178: 8183-8194, 2007.

19. Ilter A, Orem C, Balaban Yucesan F, Sahin M, Hosoglu Y, Kurumahmutoglu E, Ozer Yaman S and Orem A: Evaluation of serum sTWEAK and sCD163 levels in patients with acute and chronic coronary artery disease. Int J Clin Exp Med 8: 9394-9402, 2015.

20. Valdivielso JM, Coll B, Martin-Ventura JL, Moreno JA, Egido J, Fernández E and Blanco-Colio LM: Soluble TWEAK is associated with atherosclerotic burden in patients with chronic kidney disease. J Nephrol 26: 1105-1113, 2013.

21. Moreno JA, Muñoz-García B, Martín-Ventura JL, Madrigal-Matute J, Orbe J, Páramo JA, Ortega L, Egido J and Blanco-Colio LM: The CD163-expressing macrophages recognize and internalize TWEAK: Potential consequences in atherosclerosis. Atherosclerosis 207: 103-110, 2009.

22. Feng SL, Guo Y, Factor VM, Thorgeirsson SS, Bell DW, Testa JR, Peifley KA and Winkles JA: The Fn14 immediate-early response gene is induced during liver regeneration and highly expressed in both human and murine hepatocellular carcinomas. Am J Pathol 156: 1253-1261, 2000

23. Meighan-Mantha RL, Hsu DK, Guo Y, Brown SA, Feng SL, Peifley KA, Alberts GF, Copeland NG, Gilbert DJ, Jenkins NA, et al: The mitogen-inducible Fn14 gene encodes a type I transmembrane protein that modulates fibroblast adhesion and migration. J Biol Chem 274: 33166-33176, 1999.

24. Brown SA, Richards CM, Hanscom HN, Feng SL and Winkles JA: The Fn14 cytoplasmic tail binds tumour-necrosi s-factor-receptor-associated factors $1,2,3$ and 5 and mediates nuclear factor-kappaB activation. Biochem J 371: 395-403, 2003.

25. Saitoh T, Nakayama M, Nakano H, Yagita $H$, Yamamoto $N$ and Yamaoka S: TWEAK induces NF-kappaB2 p100 processing and long lasting NF-kappaB activation. J Biol Chem 278 36005-36012, 2003

26. Blanco-Colio LM: TWEAK/Fn14 Axis: A promising target for the treatment of cardiovascular diseases. Front Immunol 5: 3 , 2014.

27. Felli N, Pedini F, Zeuner A, Petrucci E, Testa U, Conticello C, Biffoni M, Di Cataldo A, Winkles JA, Peschle C and De Maria R: Multiple members of the TNF superfamily contribute to IFN-gamma-mediated inhibition of erythropoiesis J Immunol 175: 1464-1472, 2005.

28. Jakubowski A, Browning B, Lukashev M, Sizing I, Thompson JS Benjamin CD, Hsu YM, Ambrose C, Zheng TS and Burkly LC: Dual role for TWEAK in angiogenic regulation. J Cell Sci 115 267-274, 2002.

29. Justo P, Sanz AB, Sanchez-Niño MD, Winkles JA, Lorz C Egido J and Ortiz A: Cytokine cooperation in renal tubular cell injury: The role of TWEAK. Kidney Int 70: 1750-1758, 2006.

30. Munoz-García B, Martin-Ventura JL, Martínez E, Sánchez S, Hernández G, Ortega L, Ortiz A, Egido J and Blanco-Colio LM: Fn14 is upregulated in cytokine-stimulated vascular smooth muscle cells and is expressed in human carotid atherosclerotic plaques: Modulation by atorvastatin. Stroke 37: 2044-2053, 2006.

31. Tuttolomondo A, Di Raimondo D, Pecoraro R, Arnao V, Pinto A and Licata G: Atherosclerosis as an inflammatory disease. Curr Pharm Des 18: 4266-4288, 2012

32. Weissberg PL and Bennett MR: Atherosclerosis-an inflammatory disease. N Engl J Med 340: 1928-1929, 1999.

33. Gimbrone MA Jr and Garcia-Cardeña G: Vascular endothelium, hemodynamics, and the pathobiology of atherosclerosis. Cardiovasc Pathol 22: 9-15, 2013.

34. Harada N, Nakayama M, Nakano H, Fukuchi Y, Yagita H and Okumura K: Pro-inflammatory effect of TWEAK/Fn14 interaction on human umbilical vein endothelial cells. Biochem Biophys Res Commun 299: 488-493, 2002.

35. Shi N and Chen SY: Mechanisms simultaneously regulate smooth muscle proliferation and differentiation. J Biomed Res 28: 40-46, 2014.

36. Chistiakov DA, Orekhov AN and Bobryshev YV: Vascular smooth muscle cell in atherosclerosis. Acta Physiol (Oxf) 214 33-50, 2015.

37. Lynch CN, Wang YC, Lund JK, Chen YW, Leal JA and Wiley SR: TWEAK induces angiogenesis and proliferation of endothelial cells. J Biol Chem 274: 8455-8459, 1999.
38. Han S, Yoon K, Lee K, Kim K, Jang H, Lee NK, Hwang K and Young Lee S: TNF-related weak inducer of apoptosis receptor, a TNF receptor superfamily member, activates NF-kappa B through TNF receptor-associated factors. Biochem Biophys Res Commun 305: 789-796, 2003.

39. Mackman N: Role of tissue factor in hemostasis and thrombosis. Blood Cells Mol Dis 36: 104-107, 2006.

40. Potempa J, Korzus E and Travis J: The serpin superfamily of proteinase inhibitors: Structure, function, and regulation. J Biol Chem 269: 15957-15960, 1994.

41. Schecter AD, Spirn B, Rossikhina M, Giesen PL, Bogdanov V, Fallon JT, Fisher EA, Schnapp LM, Nemerson Y and Taubman MB: Release of active tissue factor by human arterial smooth muscle cells. Circ Res 87: 126-132, 2000.

42. Lupu F, Bergonzelli GE, Heim DA, Cousin E, Genton CY, Bachmann $\mathrm{F}$ and Kruithof EK: Localization and production of plasminogen activator inhibitor- 1 in human healthy and atherosclerotic arteries. Arterioscler Thromb 13: 1090-1100, 1993.

43. Taubman MB, Fallon JT, Schecter AD, Giesen P, Mendlowitz M, Fyfe BS, Marmur JD and Nemerson Y: Tissue factor in the pathogenesis of atherosclerosis. Thromb Haemost 78: 200-204, 1997.

44. Agirbasli M: Pivotal role of plasminogen-activator inhibitor 1 in vascular disease. Int J Clin Pract 59: 102-106, 2005.

45. Spinas E, Kritas SK, Saggini A, Mobili A, Caraffa A, Antinolfi P, Pantalone A, Tei M, Speziali A, Saggini R and Conti P: Role of mast cells in atherosclerosis: A classical inflammatory disease. Int J Immunopathol Pharmacol 27: 517-521, 2014.

46. Hansson GK: Immune mechanisms in atherosclerosis. Arterioscler Thromb Vasc Biol 21: 1876-1890, 2001.

47. Schapira K, Burkly LC, Zheng TS, Wu P, Groeneweg M, Rousch M, Kockx MM, Daemen MJ and Heeneman S: Fn14-Fc fusion protein regulates atherosclerosis in ApoE-/-mice and inhibits macrophage lipid uptake in vitro. Arterioscler Thromb Vasc Biol 29: 2021-2027, 2009.

48. Kim SH, Kang YJ, Kim WJ, Woo DK, Lee Y, Kim DI, Park YB, Kwon BS, Park JE and Lee WH: TWEAK can induce pro-inflammatory cytokines and matrix metalloproteinase-9 in macrophages. Circ J 68: 396-399, 2004.

49. Sastre C,Fernández-Laso V, Madrigal-Matute J,Muñoz-García B, Moreno JA, Pastor-Vargas C, Llamas-Granda P, Burkly LC, Egido J, Martín-Ventura JL and Blanco-Colio LM: Genetic deletion or TWEAK blocking antibody administration reduce atherosclerosis and enhance plaque stability in mice. J Cell Mol Med 18: 721-734, 2014.

50. Madamanchi NR and Runge MS: Mitochondrial dysfunction in atherosclerosis. Circ Res 100: 460-473, 2007.

51. Munzel T, Gori T, Bruno RM and Taddei S: Is oxidative stress a therapeutic target in cardiovascular disease? Eur Heart J 31: 2741-2748, 2010.

52. Scaffidi P, Misteli T and Bianchi ME: Release of chromatin protein HMGB1 by necrotic cells triggers inflammation. Nature 418: 191-195, 2002.

53. Kalinina N, Agrotis A, Antropova Y, DiVitto G, Kanellakis P, Kostolias G, Ilyinskaya O, Tararak E and Bobik A: Increased expression of the DNA-binding cytokine HMGB1 in human atherosclerotic lesions: Role of activated macrophages and cytokines. Arterioscler Thromb Vasc Biol 24: 2320-2325, 2004.

54. Andersson U, Erlandsson-Harris H, Yang H and Tracey KJ: HMGB1 as a DNA-binding cytokine. J Leukoc Biol 72: 1084-1091, 2002

55. Inoue K, Kawahara K, Biswas KK, Ando K, Mitsudo K, Nobuyoshi M and Maruyama I: HMGB1 expression by activated vascular smooth muscle cells in advanced human atherosclerosis plaques. Cardiovasc Patho 16: 136-143, 2007.

56. Kristiansen M, Graversen JH, Jacobsen C, Sonne O, Hoffman HJ, Law SK and Moestrup SK: Identification of the haemoglobin scavenger receptor. Nature 409: 198-201, 2001.

57. Jasiewicz M, Kowal K, Kowal-Bielecka O, Knapp M, Skiepko R, Bodzenta-Lukaszyk A, Sobkowicz B, Musial WJ and Kaminski KA: Serum levels of CD163 and TWEAK in patients with pulmonary arterial hypertension. Cytokine 66: 40-45, 2014.

58. Urbonaviciene G, Martin-Ventura JL, Lindholt JS, Urbonavicius S, Moreno JA, Egido J and Blanco-Colio LM: Impact of soluble TWEAK and CD163/TWEAK ratio on long-term cardiovascular mortality in patients with peripheral arterial disease. Atherosclerosis 219: 892-899, 2011. 
59. Beltran LM, Muñoz Hernández R, de Pablo Bernal RS García Morillo JS, Egido J, Noval ML, Ferrando-Martinez S, Blanco-Colio LM, Genebat M, Villar JR, et al: Reduced sTWEAK and increased sCD163 levels in HIV-infected patients: Modulation by antiretroviral treatment, HIV replication and HCV co-infection. PLoS One 9: e90541, 2014.

60. Llauradó G, González-Clemente JM, Maymó-Masip E, Subías D, Vendrell J and Chacón MR: Serum levels of TWEAK and scavenger receptor CD163 in type 1 diabetes mellitus: Relationship with cardiovascular risk factors. A case-control study. PLoS One 7: e43919, 2012.

61. Van Gorp H, Delputte PL and Nauwynck HJ: Scavenger receptor CD163, a Jack-of-all-trades and potential target for cell-directed therapy. Mol Immunol 47: 1650-1660, 2010.

62. Kowal K, Silver R, Sławińska E, Bielecki M, Chyczewski L and Kowal-Bielecka O: CD163 and its role in inflammation. Folia Histochem Cytobiol 49: 365-374, 2011.

63. Moller HJ, Nielsen MJ, Maniecki MB, Madsen $M$ and Moestrup SK: Soluble macrophage-derived CD163: A homogenous ectodomain protein with a dissociable haptoglobin-hemoglobin binding. Immunobiology 215: 406-412, 2010

64. Etzerodt A and Moestrup SK: CD163 and inflammation: Biological, diagnostic, and therapeutic aspects. Antioxid Redox Signal 18: 2352-2363, 2013

65. Backe E, Schwarting R, Gerdes J, Ernst $M$ and Stein H: Ber-MAC3: New monoclonal antibody that defines human monocyte/macrophage differentiation antigen. J Clin Pathol 44: 936-945, 1991.

66. Chamorro S, Revilla C, Alvarez B, Alonso F, Ezquerra A and Domínguez J: Phenotypic and functional heterogeneity of porcine blood monocytes and its relation with maturation. Immunology 114: 63-71, 2005.

67. Baeten D, Møller HJ, Delanghe J, Veys EM, Moestrup SK and De Keyser F: Association of CD163+ macrophages and local production of soluble CD163 with decreased lymphocyte activation in spondylarthropathy synovitis. Arthritis Rheum 50: 1611-1623, 2004.

68. Bronkhorst IH, Ly LV, Jordanova ES, Vrolijk J, Versluis M, Luyten GP and Jager MJ: Detection of M2-macrophages in uveal melanoma and relation with survival. Invest Ophthalmol Vis Sci 52: 643-650, 2011.

69. Ratcliffe NR, Kennedy SM and Morganelli PM: Immunocytochemical detection of Fcgamma receptors in human atherosclerotic lesions. Immunol Lett 77: 169-174, 2001.

70. Högger P, Dreier J, Droste A, Buck F and Sorg C: Identification of the integral membrane protein RM3/1 on human monocytes as a glucocorticoid-inducible member of the scavenger receptor cysteine-rich family (CD163). J Immunol 161: 1883-1890, 1998.

71. Sulahian TH, Högger P, Wahner AE, Wardwell K, Goulding NJ, Sorg C, Droste A, Stehling M, Wallace PK, Morganelli PM and Guyre PM: Human monocytes express CD163, which is upregulated by IL-10 and identical to p155. Cytokine 12: 1312-1321, 2000.

72. Timmermann $\mathbf{M}$ and Högger P: Oxidative stress and 8-iso-prostaglandin $\mathrm{F}$ (2alpha) induce ectodomain shedding of CD163 and release of tumor necrosis factor-alpha from human monocytes. Free Radic Biol Med 39: 98-107, 2005.

73. Zwadlo G, Voegeli R, Schulze Osthoff K and Sorg C: A monoclonal antibody to a novel differentiation antigen on human macrophages associated with the down-regulatory phase of the inflammatory process. Exp Cell Biol 55: 295-304, 1987.

74. Buechler C, Ritter M, Orsó E, Langmann T, Klucken J and Schmitz G: Regulation of scavenger receptor CD163 expression in human monocytes and macrophages by pro- and antiinflammatory stimuli. J Leukoc Biol 67: 97-103, 2000.

75. Van den Heuvel MM, Tensen CP, van As JH, Van den Berg TK, Fluitsma DM, Dijkstra CD, Döpp EA, Droste A, Van Gaalen FA, Sorg C, et al: Regulation of CD 163 on human macrophages: Cross-linking of CD163 induces signaling and activation. J Leukoc Biol 66: 858-866, 1999.

76. Schaer DJ, Boretti FS, Schoedon G and Schaffner A: Induction of the CD163-dependent haemoglobin uptake by macrophages as a novel anti-inflammatory action of glucocorticoids. $\mathrm{Br}$ Haematol 119: 239-243, 2002.
77. Varga G, Ehrchen J, Tsianakas A, Tenbrock K, Rattenholl A, Seeliger S, Mack M, Roth J and Sunderkoetter C: Glucocorticoids induce an activated, anti-inflammatory monocyte subset in mice that resembles myeloid-derived suppressor cells. J Leukoc Biol 84: 644-650, 2008

78. Hogger P, Erpenstein U, Rohdewald P and Sorg C: Biochemical characterization of a glucocorticoid-induced membrane protein (RM3/1) in human monocytes and its application as model system for ranking glucocorticoid potency. Pharm Res 15: 296-302, 1998.

79. Weaver LK, Pioli PA, Wardwell K, Vogel SN and Guyre PM: Up-regulation of human monocyte CD163 upon activation of cell-surface Toll-like receptors. J Leukoc Biol 81: 663-671, 2007.

80. Hintz KA, Rassias AJ, Wardwell K, Moss ML, Morganelli PM, Pioli PA, Givan AL, Wallace PK, Yeager MP and Guyre PM: Endotoxin induces rapid metalloproteinase-mediated shedding followed by up-regulation of the monocyte hemoglobin scavenger receptor CD163. J Leukoc Biol 72: 711-717, 2002.

81. Gleissner CA, Shaked I, Erbel C, Böckler D, Katus HA and Ley K: CXCL4 downregulates the atheroprotective hemoglobin receptor CD163 in human macrophages. Circ Res 106: 203-211, 2010.

82. Levy AP and Moreno PR: Intraplaque hemorrhage. Curr Mol Med 6: 479-488, 2006.

83. Virmani R, Kolodgie FD, Burke AP, Finn AV, Gold HK, Tulenko TN, Wrenn SP and Narula J: Atherosclerotic plaque progression and vulnerability to rupture: Angiogenesis as a source of intraplaque hemorrhage. Arterioscler Thromb Vasc Biol 25: 2054-2061,2005.

84. Schaer DJ and Buehler PW: Cell-free hemoglobin and its scavenger proteins: New disease models leading the way to targeted therapies. Cold Spring Harb Perspect Med 3: pii:a013433, 2013.

85. Madsen M, Møller HJ, Nielsen MJ, Jacobsen C, Graversen JH, van den Berg T and Moestrup SK: Molecular characterization of the haptoglobin.hemoglobin receptor CD163. Ligand binding properties of the scavenger receptor cysteine-rich domain region. J Biol Chem 279: 51561-51567, 2004.

86. Schaer CA, Schoedon G, Imhof A, Kurrer MO and Schaer DJ: Constitutive endocytosis of CD163 mediates hemoglobin-heme uptake and determines the noninflammatory and protective transcriptional response of macrophages to hemoglobin. Circ Res 99: 943-950, 2006.

87. Philippidis P, Mason JC, Evans BJ, Nadra I, Taylor KM, Haskard DO and Landis RC: Hemoglobin scavenger receptor CD163 mediates interleukin-10 release and heme oxygenase-1 synthesis: Antiinflammatory monocyte-macrophage responses in vitro, in resolving skin blisters in vivo, and after cardiopulmonary bypass surgery. Circ Res 94: 119-126, 2004.

88. Nielsen MJ, Møller HJ and Moestrup SK: Hemoglobin and heme scavenger receptors. Antioxid Redox Signal 12: 261-273, 2010.

89. Polek TC, Talpaz M, Darnay BG and Spivak-Kroizman T: TWEAK mediates signal transduction and differentiation of RAW264.7 cells in the absence of Fn14/TweakR. Evidence for a second TWEAK receptor. J Biol Chem 278: 32317-32323, 2003.

90. Burkly LC, Michaelson JS, Hahm K, Jakubowski A and Zheng TS: TWEAKing tissue remodeling by a multifunctional cytokine: Role of TWEAK/Fn14 pathway in health and disease. Cytokine 40: 1-16, 2007.

91. Moreno JA, Dejouvencel T, Labreuche J, Smadja DM, Dussiot M, Martin-Ventura JL, Egido J, Gaussem P, Emmerich J, Michel JB, et al: Peripheral artery disease is associated with a high CD163/TWEAK plasma ratio. Arterioscler Thromb Vasc Biol 30: 1253-1262, 2010.

92. Kowal-Bielecka O, Bielecki M, Guiducci S, Trzcinska-Butkiewicz B, Michalska-Jakubus M, Matucci-Cerinic M, Brzosko M, Krasowska D, Chyczewski L and Kowal K: High serum sCD163/sTWEAK ratio is associated with lower risk of digital ulcers but more severe skin disease in patients with systemic sclerosis. Arthritis Res Ther 15: R69, 2013.

93. Møller HJ: Soluble CD163. Scand J Clin Lab Invest 72: 1-13, 2012.

94. Goldstein JL and Brown MS: Regulation of the mevalonate pathway. Nature 343: 425-430, 1990. 